Check for updates

School of Nursing and Midwifery, Queen's University Belfast, Belfast, UK

2 Philip Darbyshire Consulting, Adelaide, South Australia, Australia

david.thompson@qub.ac.uk Cite this as: BMJ 2020;370:m2721 http://dx.doi.org/10.1136/bmj.m2721 Published: 09 July 2020

\title{
ESSAY
}

\section{Nightingale's year of nursing: rising to the challenges of the covid-19 era}

\begin{abstract}
WHO designated 2020 the year of nursing, little knowing that the pandemic would soon change health professions universally. The events offer an opportunity to reform a beleaguered profession as full of potential and passion as its founder, write David R Thompson and Philip Darbyshire
\end{abstract}

\section{David R Thompson, ${ }^{1}$ Philip Darbyshire ${ }^{2}$}

There is much to celebrate on the 2ooth anniversary of the birth of Florence Nightingale, social reformer, statistician, pioneer, and founder of modern nursing. ${ }^{1}$ She laid the foundation of professional nursing with the establishment of the first secular nursing school at St Thomas' Hospital in London. Her popular but overly romanticised image as "the lady with the lamp” in Scutari during the Crimean war is widely known, and her influential Notes on Nursing and Notes on Hospitals remain respected works. ${ }^{2}$ Less well known are her proposals for fundamental social reform of the poor laws and workhouses into precursors of the welfare state and her role as a pioneer statistician.

Despite criticisms, mythologising and demythologising, Nightingale's legacy endures and continues to influence contemporary nursing. ${ }^{3}$ The NHS Nightingale Hospitals for patients with covid-19 were named for good reason. She envisioned a public healthcare system based on health promotion and disease prevention and was unafraid to challenge outdated systems and practices, be they from the military, medical, or political establishment. And yet, it is exactly this kind of influence her profession needs more than ever. Nurses today make up the world's largest healthcare workforce. They have the potential to transform how care is delivered-but only if they can be unshackled from what the profession has become.

\section{Self-sabotage}

For a profession that prides itself on values such as caring and compassion-and the leaders and managers of which frequently extol such virtues-we, both long serving nurses, continue to be saddened by the frequent reports we receive of repeated, endemic, and systemic bullying, intimidation, and harassment.

This oppression and gaslighting of, usually but by no means exclusively, junior, enthusiastic, novice nurses is widespread in both clinical practice and academia. ${ }^{4}$ Numerous examples have been conveyed to us over decades of "cult of personality" management styles used by senior managers and their acolytes, who seek to thwart ambition, suppress dissent, stifle creativity, and generally subvert and punish any perceived competition or lack of adulation. $^{5}$
Over the past 50 years, there have been numerous failed reorganisations, changes of roles and responsibilities, grandiose job titles and launches, often to great fanfare, of supposedly new initiatives. These "announceables" are often unevaluated and rarely enduring or impactful. ${ }^{6} \mathrm{~A}$ prime example is the introduction of the modern matron. ${ }^{7}$ Despite the frequent platitudes and exhortations from chief nursing officers, directors of nursing, and deans of nursing for "re-engineering" of services and "transformational leadership," the reality is that for many nurses, poor leadership, a "command and control" culture, punitive management, minimal mentorship, and blighted career development are endemic in the profession.

Even now, in the teeth of a pandemic that has killed at least 200 healthcare workers in the UK alone and is taking a toll on the physical and mental health and wellbeing of those still working, and their families, the playbook of command and control bullies remains operational. Hospitals globally are gagging staff who attempt to raise concerns around personal protective equipment, staffing, or conditions. Chief executive officers, executive groups, and their human resources and communications departments intimidate and deter staff with threats of disciplinary action or even dismissal should they make any public comment about the situation.

Health ministers and chief nurses should be supporting their frontline staff and outlawing these threats, but their silence has been deafening. Continued attempts to gag and control nurses does not bode well for the leading role that nurses will be expected to take in post-covid-19 rebuilding.

This well recognised "toxic triangle" (destructive leaders, susceptible followers, and conducive environments) ${ }^{8}$ plays out against a backdrop of global nursing facing an acute shortage of nurses, increased expectations and demands, and ever changing political diktats. Nurses are leaving our profession in droves, not because they no longer like nursing or have other career aspirations but because they feel burnt out, devalued, damaged, and disenchanted. They have not left nursing-nursing and its assumed values have left them.

Despite this, nursing remains institutionally tone deaf to bullying and harassment. Pervasive patterns 
of abuse are consistently denied, dismissed, and deflected..$^{10}$

Although there is no shortage of pledges, policies, and platitudes about how officially unacceptable bullying and harassment are, there are no clear, consistently applied, effective, national policies in any country that have been designed or shown to eradicate bullying. Most bullies continue to enjoy a career for life. It is the exception rather than the rule that a bully's behaviour costs them their job, power, status, or registration.

Unless the bullies, rather than the bullied, are driven out of nursing, we will still have this problem on Florence Nightingale's

tricentenary. As Nightingale herself urged: "I think one's feelings waste themselves in words; they ought all to be distilled into actions which bring results." 11

\section{A force for all}

If we have learnt one vital lesson from the covid-19 crisis, it is that nurses, doctors, and health systems need no lessons on change management or disruption. The changes that they have responded to and achieved in the past few months have been seismic. What has been achieved by genuine, urgent collegiality and cooperation and by rewriting or jettisoning the policy rulebooks telling us that things could not possibly be done is breathtaking. Many health professionals are already saying that we can never return to the bureaucratic inertia and tribalism that made many of our hospitals and health systems almost lost causes.

We must embed this new collaboration and mutual respect into re-energised organisational systems and cultures that benefit doctors, nurses, and patients. Our medical colleagues can and should help us realise this challenge. Don't just bring us cake, bring us into decision making and every clinical forum in which care is determined. Don't just ask what we've done for a patient, ask for our judgment regarding their clinical situation and progress. Don't just ignore a nurse being berated or humiliated, step in and we will repay the professional courtesy if we see a doctor being similarly mistreated. That is what team mates do for each other.

Don't value us only as helpers but as peers and colleagues who do different but equally valuable work. Nurses make major contributions to healthcare, particularly in health promotion, risk reduction, disease prevention, and management. They have taken service leading roles across a broad range of preventive, intervention, and follow-up services that have demonstrably improved public health. In areas such as wound care, cancer care, palliative care, pain management, rehabilitation, and mental health, nurses have often been not simply followers and adopters but service pioneers. $^{12}$

\section{Not alone}

The World Health Organization's State of the World's Nursing 2020 report shows that nursing is ideally placed to tackle forthcoming health challenges: ageing populations, multimorbidity, frailty, mental health, infectious and non-communicable diseases, social exclusion and addiction, and prevention of, and response to, future pandemics. But change in working practice is needed. ${ }^{12}$

Such change poses major professional and organisational challenges for all of us, often operating in isolation with limited resources and stifled by corporate agendas that rarely permit individual thinking, creativity, or flexibility, preferring rigid "groupthink," policies, and procedures. This is a recurring motif in health service scandals such as Mid-Staffordshire and Gosport, where nurses routinely felt unable or unwilling to challenge overbearing, bullying behaviour from colleagues or to intervene when patients' safety or even lives were in danger. ${ }^{13}$

Nurses should be able to focus on their fundamental purpose of improving the health and wellness of the people, families, and communities they serve. To do this, they need managers, leaders, and an organisational culture that are at their service, not at their throat.

We need more nurses of the calibre of Florence Nightingale-passionate and tenacious, unafraid to take risks, willing to challenge the powerful, driving genuine change, building strong teams, inspiring and bringing others with them. The best of Nightingale's legacy, "less of the icon and more of the iconoclast," deserves to endure for another 200 years.

\section{Biography}

David R Thompson and Philip Darbyshire are nurses, each with nearly 50 years of experience in clinical practice, management, and academia. They are passionate about nursing and want it to be properly recognised, valued, and supported for its contribution to health and healthcare before they retire.

Competing interests: All authors declare that the answer to the questions on your competing interest form (https://bmj.com/cgi/content/full/317/7154/291/DC1) are all no and therefore have nothing to declare.

McDonald L. Mythologizing and de-mythologizing. In: Nelson S, Rafferty AM, eds. Notes on Nightingale: the influence and legacy of a nursing icon. Cornell University Press, 2010: 91-114.

2 Rafferty AM, Wall R. An icon and iconoclast for today. In: Nelson S, Rafferty AM, eds. Notes on Nightingale: the influence and legacy of a nursing icon. Cornell University Press, 2010: 130-41. Williams K. Reappraising Florence Nightingale. BMJ2008;337:a2889.

doi: 10.1136/bmj.a2889 pmid: 19088144

Darbyshire P, Thompson DR, Watson R. Nursing's future? Eat young. Spit out. Repeat. Endlessly. J Nurs Manag 2019;27:1337-40. doi: 10.1111/jonm.12781 pmid: 31012191

Darbyshire P, Thompson DR, Watson R. Nursing schools: dumbing down or reaching up?J Nurs Manag 2019;27:1-3. doi: 10.1111/jonm.12730 pmid: 30422381

6 Smith J, Walshe K, Hunter DJ. The "redisorganisation" of the NHS. BMJ2001;323:1262-3. doi: 10.1136/bmj.323.7324.1262 pmid: 11731374

7 Wildman S, Hewison A. Rediscovering a history of nursing management: from Nightingale to the modern matron. Int J Nurs Stud 2009:46:1650-61.

doi: 10.1016/j.jinurstu.2009.06.008 pmid: 19596321

8 Padilla A, Hogan R, Kaiser RB. The toxic triangle: destructive leaders, susceptible followers, and conducive environments. Leadersh Q2007;18:176-94doi: 10.1016/j.leaqua.2007.03.001.

9 Rowe MM, Sherlock H. Stress and verbal abuse in nursing: do burned out nurses eat their young?) Nurs Manag 2005;13:242-8. doi: 10.1111/j.1365-2834.2004.00533.x pmid: 15819837

10 Lim FA, Bernstein I. Civility and workplace bullying: resonance of Nightingale's persona and current best practices. Nurs Forum 2014;49:124-9. doi: 10.1111/nuf.12068 pmid: 24955475

11 Nightingale F. 1844 Letter to a friend. In: Cook E, ed. The life of Florence Nightingale. Macmillan \& Co Ltd, 1913: 94

12 World Health Organization. State of the world's nursing 2020: investing in education, jobs and leadership. WHO, 2020

13 Darbyshire P, Thompson D. Gosport must be a tipping point for professional hierarchies in healthcare-an essay by Philip Darbyshire and David Thompson. BMJ2018;363:k4270. doi: 10.1136/bmi.k4270 pmid: 32043471

This article is made freely available for use in accordance with BMJ's website terms and conditions for the duration of the covid-19 pandemic or until otherwise determined by BMJ. You may use, download and print the article for any lawful, non-commercial purpose (including text and data mining) provided that all copyright notices and trade marks are retained. 